\title{
Prevenção da Desnutrição Energético-protéica
}

\author{
Malaquias Batista Filho* \\ Susana Inez Bleil ** \\ Lea Maria Van Eysden **
}

Descreve-se, de forma abreviada, a evolução de conceito de prevenção na área de saúle e suas implicaçōes com as políticas e programas, objetivando o controle da desnutriçāo energético-protéica (DEP). Partindo-se do enfoque reducionista, considera-se a efetividade de intervençôes propostas, segundo sua lógica e a experiência de alguns países. Reconhece-se $o$ caráter conjuntural das medidas unissetoriais de saúde, assumindo-se a conduta "holística" como a mais válida e legitima para fundamentar os programas de prevenção da DEP, nos países subdesenvolvidos.

\section{INTRODUÇÃO}

Em seu conceito clássico, considera-se como prevenção o conjunto de medidas circunscritas à área de saúde, que devem ser mobilizadas, a nível de indivíduos, coletividades humanas e seu ambiente, com o objetivo de evitar o aparecimento das doenças. O termo "profilaxia" expressa bem o significado da prevenção convencional.

Em sentido mais abrangente, segundo os postulados de Leavell/Clark, as nedidas preventivas seriam categorizadas em níveis (primário, secundário e terciário), representando o primeiro (medidas de promoção e proteção específicas de saúde) o próprio conceito da profilaxia tradicional. A limitaçáo do dano e a reabilitação física e social seriam também açōes "preventivas", na medida em que evitam o agravamento do processo mórbido ou reduzem as conseqüências tardias de sua evolução patogênica (10).

Por fim, sob a ótica mais atual, o processo saúde/ doença passa a ser entendido, em seu sentido integral, dentro de uma lógica compreensiva. A epidemiologia social, na medida em que questiona os níveis de saúde

* Professor Adjunto do Departamento de Nutriçâo da Universidade Federal de Pernambuco. Bolsista do CNPq.

* Nutricionistas, Escola Nacional de Saúde Pública/FIOCRUZ, Rio de Janeiro. e suas relações com as estruturas e funçōes da sociedade, amplia e até mesmo universaliza a abordagem dos problemas setoriais, identificando-os com a qualidade de vida da população. Este posicionamento implica um compromisso político e ideológico mais totalizante e profundo na análise e tratamento dos problemas de saúde. $(7,12)$

Cadernos de Saúde Pública, RJ, 5(3): 276-283, jul/set, 1989 
É claro que a abordagem "preventiva" da desnutrição energético-protéica (DEP), como de outros problemas de saúde, muda de enfoque e por conseqüência, de proposição programática em função da perspectiva conceitual que se assume. Na prática, porém, o que se constata é o discurso dos governos e das instituições intemacionais, tendo como apoio a posição estruturalista, enquanto os programas e açōes tendem a se limitar ao setor saúde, e muito freqüentemente, às medidas de prevenção secundária do esquema de Leavell/Clark.

\section{O MODELO CAUSAL}

Seja qual for a perspectiva de abordagem, a prevençāo da desnutrição energético-protéica e de outros problemas da nutriçāo deve partir do modelo causal que condiciona a situação. É o maior ou menor aprofundamento dos níveis explicativos e sua incorporação nas decisões políticas e açōes programáticas que distingue o caráter e a abrangência das medidas preventivas.

A seguir, expōe-se, de forma simplificada, o modelo causal da desnutrição energético-protéica (DEP).

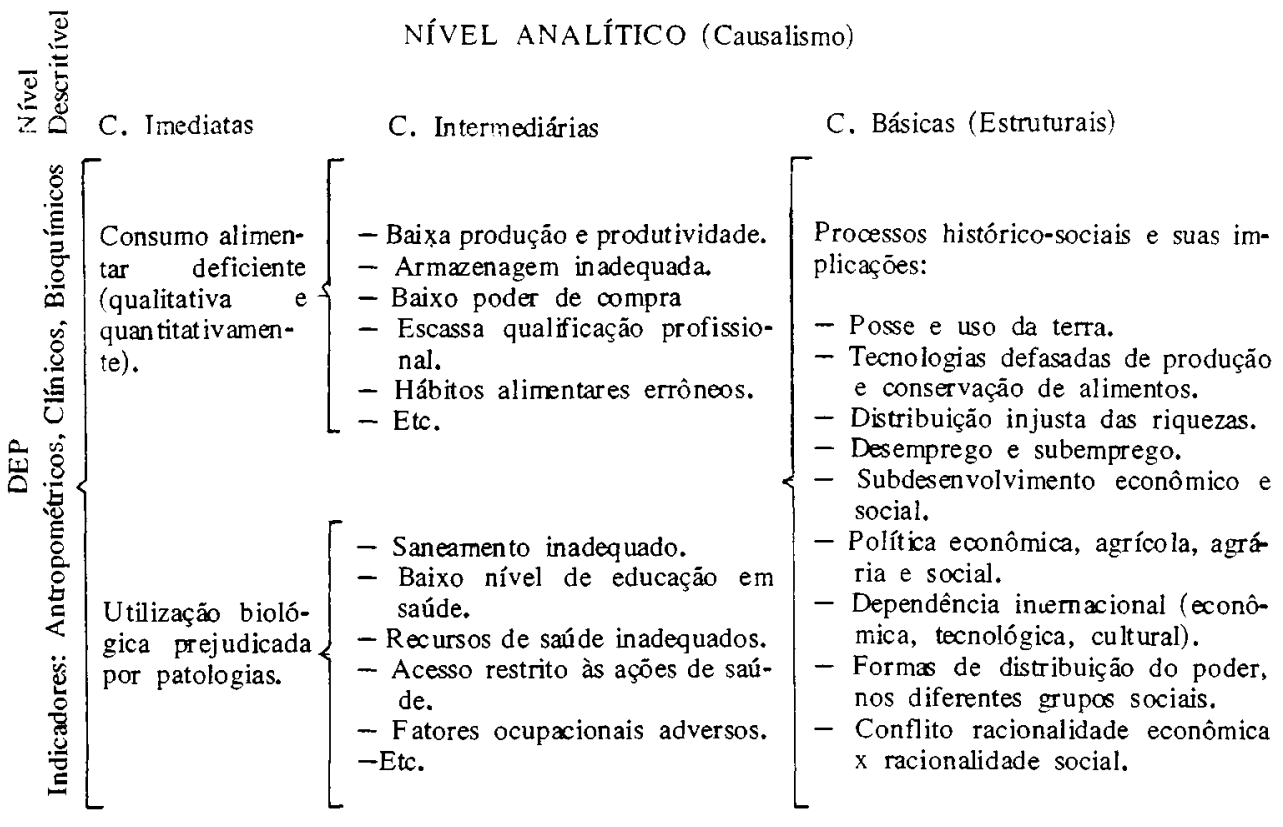


Historicamente, a tendência é a alocação de medidas em aspectos pontuais das causas mais imediatas. Sob o ponto de vista operacional, a proposta das chamadas "ações integradas de saúde" exemplifica bem o caráter intervencionista e particularizante desta concepçāo. Em alguns países incluem-se açōes cobrindo as chamadas causas intermediárias ou imediatas. São mais raras as decisões políticas, alcançando as causas básicas que, muitas vezes, só podem ser removidas mediante alterações revolucionárias no processo econômico, social e político, como em Cuba e na China.

\section{O PAPEL DO SETOR SAÚDE}

Sob o aspecto conceitual, é evidente que a forma mais eficiente de controlar a DEP seria através de intervençōes e mudanças simultâneas nos diferentes fatores que compõem a cadeia de causação. Isto nem sempre é possível, embora seja sempre desejável.

No que se refere de forma específica ao setor saúde, sua competência se circunscreve, na prática, às ações básicas que se situariam no âmbito das causas intermediárias, trazendo como contribuição a redução de agravos patológicos, sobretudo de natureza infecciosa. O alcance dessas açóes, a nível de utilização biológica de energia e nutrientes, pode ser de considerável relevância para o controle da desnutrição (9). Secundariamente, o setor saúde pode assumir algum papel direto ou indireto em termos de melhoria do consumo alimentar, como no caso da suplementação de grupos biológicos de elevado risco (gestantes, nutrizes e crianças), na indução de hábitos de consumo mais inteligentes, na promoção do aleitamento materno, no estabelecimento de normas sobre enriquecimento de alimentos e seu controle. Esta contribuição, no entanto, deve ser bem menos relevante que a função de evitar, diagnosticar e tratar precocemente doenças que comprometem a utilização adequada de alimentos $(3,9)$.

Como instrumento de intervenção isolada, a participação do setor saúde, adstrita às atividades acima indicadas, representa uma compreensão reducionista e incompleta do problema nutricional. Todavia pode significar, a curto prazo, uma estratégia de elevada eficácia, custo reduzido e ampla cobertura aos grupos de alto risco. Por outro lado - e até mesmo com maior razão e consistência doutrinária - não se descarta, mas antes se valoriza, a contribuição setorial da saúde aos programas "holísticos", nos quais os objetivos e estratégias de alimentação e nutrição acham-se incluídos nas próprias prioridades e estratégias das políticas de desenvolvimento econômico e social do

Cadernos de Saúde Pública, RJ, 5(3): 276-283, jul/set, 1989 
País, isto é, no corpo de decisōes que atuariam sobre as causas intermediárias e básicas ou estruturais da desnutrição (11).

Posta como al temativa teórica, a política "holística" representa, sem dúvida, a formulação ideal das propostas de combate aos problemas de desnutrição $(5,6)$. A restrição do modelo consiste, justamente, na dificuldade de sua implementação, por razões bem evidentes. No estágio econômico, social, político e administrativo em que se encontra a maioria dos países subdesenvolvidos, a hipótese mais realista de trabalho a curto prazo consistiria em exercitar, de forma adequada, alguns instrumentos previstos na concepção intervencionista e, de modo especial, na otimização das ações básicas de saúde. Ao mesmo tempo deve-se trabalhar no plano político para apressar as mudanças do processo económico e social, construindo as bases para que a desnutrição endêmica seja controlada pela supressão completa de sua cadeia de fatores causais. (4)

\section{ALGUMAS EXPERIÊNCIAS}

É indiscutível a gênese social da desnutrição. Só como exceção aparecem casos de crianças desnutridas nas famílias de padrão sócio-econômico elevado, assim mesmo com caráter secundário, quase sempre condicionados por doenças graves.

A aplicação criteriosa e sistemática de um elenco reduzido de açōes, através de serviços de saúde racionalmente concebidos e operados, pode produzir resultados substanciais na prevenção da DEP. A lógica destas açōes respalda-se no sinergismo desnutrição/ infecção $\mathrm{e}$, em conseqüência, no efeito interativo das medidas aplicáveis a cada um dos termos deste binômio.

BERG relatou, há algum tempo, 10 projetos bemsucedidos, em escala experimental, em diversos países (6). Hoje existem, no entanto, excelentes programas em operação, a nível nacional ou regional.

A experiência do Chile é muito ilustrativa a este respeito (1). Aproveitando a excelente estrutura, organização, planejamento, normas de trabalho e tradicional competência de seus técnicos e administradores de saúde, aquele país pôde reverter o grave quadro nutricional prevalente há 15 anos, alcançando um estágio em que a DEP pode ser considerada sob controle. Isto a despeito da desfavorável situação econômica e social, agravada nos últimos anos do govemo militar. O Sistema de Vigilância Alimentar e Nutricional do Chile, possibilitando a cada mês um diagnóstico "fatorizado" do estado de nutrição das crianças (sob a ótica de fatores imediatos da condição de saúde) é um bom exemplo, um exemplo didático mesmo, da competência

Cadernos de Saúde Pública, RJ, 5(3): 276-283, jul/set, 1989 
do setor saúde. É um fato que é necessário reconhecer e analisar.

O caso de Costa Rica é também muito convincente. Apesar de ter uma renda "per capita" de 1.800 dólares anuais ( $10 \%$ abaixo da brasileira) e do caráter extremamente dependente de sua economia, o país reduziu de $12 \%$ para $4 \%$ a prevalência da desnutrição de II e III graus no prazo de 10 anos, enquanto o coeficiente de mortalidade infantil caiu de valores próximos a 60 para 18 por 1.000 crianças nascidas vivas.

A nosso ver, um dos programas mais sugestivos é o do Norte da Argentina, uma área tão pobre como o Nordeste brasileiro (2). Um bem concebido e aplicado programa de Atenção Primária de Saúde, incluindo atividades específicas de nutrição, possibilitou a redução da DEP de uma prevalência inicial de $21 \%$ para $5-7 \%$ no espaço de cinco anos. No mesmo período, nas áreas cobertas pela APS, em Salta, a mortalidade infantil foi reduzida de um coeficiente inicial de 150 para 53 por 1.000 nascidos vivos. O gráfico seguinte ilustra a evoluçāo temporal do estado de nutriçăo das crianças sob controle do programa.

\section{REPÚBLICA ARGENTINA}

Programa de atenção primária de saúde

- percentagem de crianças de $0-5$ anos, desnutridas -

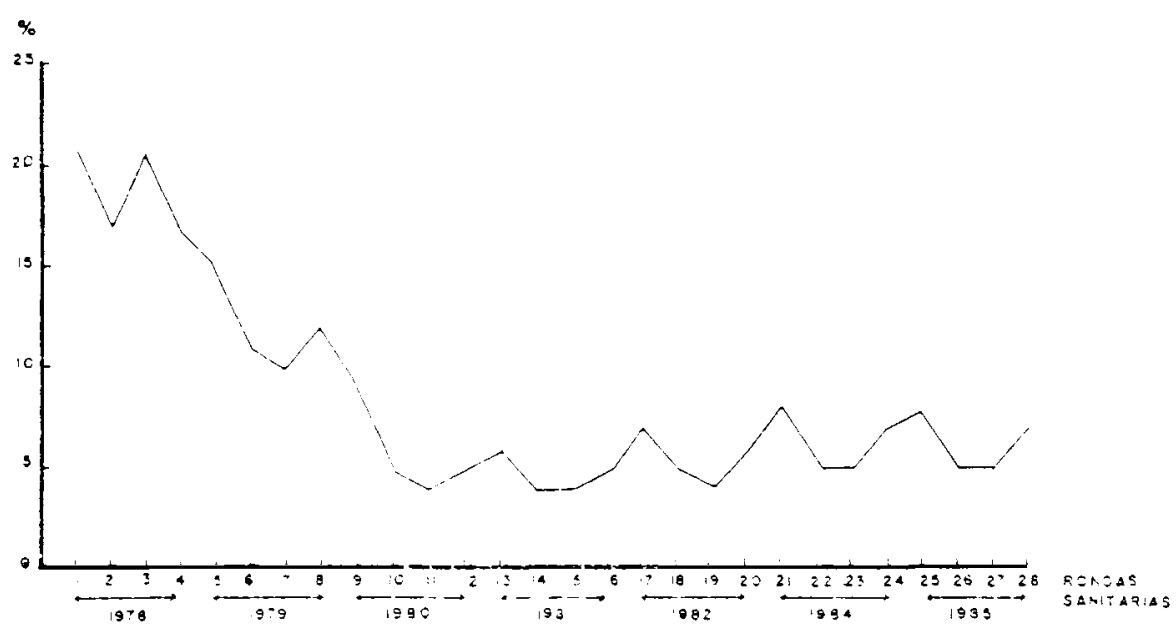


Comenta-se, também, como um trabalho bem-sucedido, o programa de nutrição desenvolvido nas Filipinas (5), a respeito das dificuldades econômicas e da turbulência política. Estes exemplos, além de experiências em menor escala na Índia, Guatemala, Nigéria e outros países concretizam, através de resultados bem expressivos, a postulação de BERG, indicando que o setor saúde ainda não esgotou sua contribuição potencial à solução do problema da desnutrição (6).

Pode-se estimar que, mesmo na vigencia das condiçōes econômicas e sociais precárias e indesejáveis dos países subdesenvolvidos, seria plenamente possível reduzir entre $50 \%$ e $85 \%$ a prevalência de formas moderadas e graves da DEP. A aplicação criteriosa de ações básicas de saúde - incentivo ao aleitamento matemo, cobertura vacínica, combate às diarréias através da terapia de hidratação oral e medidas complementares, vigilância do processo de crescimento e combate a infecções respiratórias agudas - pode representar uma contribuição de grande valia na redução da DEP.

Como ilustração da abordagem globalista, dois exemplos, infelizmente pouco divulgados no ocidente ou pelo menos no Brasil. São os casos de Cuba e da China, países que fizeram uma radical revolução política e social há poucas décadas. Não há mais desnutrição como problema de saúde coletiva nessas naçōes socialistas do III mundo. A renda "per capita" de Cuba ainda é inferior à do Brasil. Todavia, o problema nutricional que agora se configura na instigante experiência cubana é o da obesidade infanto-juvenil. A mortalidade infantil foi rebaixada para $14 / 00$, aproximando-se da dos Estados Unidos, apesar dos 14.000 dólares de renda "per capita" dos norte-americanos. $\mathrm{Na}$ China, há mais de 10 anos, segundo depoimento GRAVIOTO, (8) a desnutrição acha-se sob controle, sem embargo do desempenho ainda precário da economia, produzindo apenas 300 dólares "per capita", além da enorme complexidade administrativa de um País com mais de 1 bilhão de habitantes, a grande maioria vivendo no campo onde, teoricamente, são maiores os obstáculos para se levar a toda a população os beneficios do desenvolvimento científico e tecnológico.

\section{CONCLUSÕES}

- O conceito e as estratégias de prevenção da desnutrição variam em função das doutrinas dominantes em termos de pensamento e política de saúde, assumindo, em razão de cada posicionamento, espaços e sentidos diferentes dentro do modelo causal do problema. 
- Em que pese o caráter reducionista e até alienado do chamado enfoque "intervencionista", a lógica epidemiológica e os resultados de algumas experiências bem-concebidas e aplicadas indicam tratar-se de uma alternativa de considerável eficácia no combate à desnutrição.

- Exemplos de países capitalistas e socialistas econômica e tecnicamente atrasados parecem indicar que, independente da perspectiva ideológica, o que decide o êxito dos programas de nutrição é a aplicação judiciosa dos instrumentos de intervenção, dentro de normas técnicas estabelecidas. Pods:-se esperar que, por si só, a aplicação integrada das medidas de atenção primária de saúde reduzam de $50 \%$ a $85 \%$ a prevalência de formas moderadas e graves de desnutriçáo energético-protéica.

- A compreensão "holística" representa a abordagem mais consistente e legítima (embora também a mais dificil) para o controle efetivo e permanente da desnutrição.

This paper gives a concise description of the evolution undergone by the concept of prevention in the health field and its involvement in the policies and programs that aim at controlling the malnutrition. The effectiveness of some proposed interventions is considered in accordance with their logic and the experience developed by some countries. While recognizing the conjunctional character of one-sided measures taken to solve health problems, the holistic point of view is adopted as the most legitimate and valid behaviour to establish the basis of preventive programs for solving energetic-proteinic malnutrition in developing countries.

\section{REFERÊNCIAS BILBIOGRÁFICAS}

1. A LIAGA, H. Sistema de Vigilância Alimentaria y Nutricional - Chile. II Mesa-Redonda sobre Sistema de Vigilancia A limentária y Nutricional en A mérica Latina y Caribe. Bogotá, Colonbia, 1987.

2. ANDRE DE MATEO, S. et alii. Programa de Vigilancia Epidemiológica Nutricional en la Población de 0-5 Años: Salta, Republica Argentina. Anais do Seminário sobre Atenção Primária de Saúde. Recife, 1985.

3. BATISTA FILHO, M e BARBOSA, N. P. Alimentaçāo e Nutrição no Brasil. Pró-Memória: 1974-1984. Canadá Gráfica e Editora, Brasília, 1985.

4. BATISTA FILHO, M. Saúde e Nutrição. In: ROUQUAYROL, Z. M. Epidemiologia \& Saúde. 2: Ed., MEDSI, $R$ io de Janeiro, 1986. 
5. BEGHIN, I, et alii. Desnutrición, desarollo nacional y planificación. Boletin de la Oficina Sanitaria Pan-Americana, 89 (6): 505-15, Washington, 1980.

6. BERG, A. Los malnutridos. Examen de políticas. BIRD, Serie sobre la pobreza y las necesidades básicas, Washington, 1984.

7. BREILH, P. J. Epidemiologia: economia, medicina y política. SESPAS, Santo Domingo, Rep. Dominic ana, 1981.

8. GRAVIOTO, J. Comunicaçăo pessoal.

9. KENNEDY, E. T. and ALDERMAN, H. H. Comparative analyses of nutritional effectiveness of food subsidies and other food-related interventions. International Food Policy Research Institut, joint WHO-U NICEF Nutrition, Washington, 1987.

10. LEA VELL, H. e CLARK, E. Q. Medicina Preventiva (Tradução). Mc Graw-Hill. São Paulo, 1976.

11. PIKE, R. L. and BROWN, M. L. Nutrition: an integral approach. Second Ed.; J. WILEY, 1975.

12. ROUQUA YROL, Z. M. Épidemiologia \& Saúde. 2! Ed.; MEDSI, Rio de Janeiro, 1986. 